\title{
DESENVOLVIMENTO DE UMA METODOLOGIA PARA A OBTENÇÃO DE MELITINA A PARTIR DO VENENO DE ABELHA
}

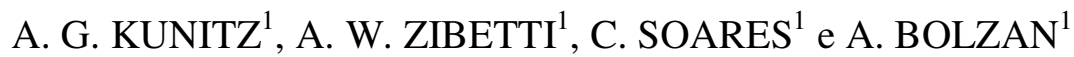 \\ ${ }^{1}$ Universidade Federal de Santa Catarina, Departamento de Engenharia Química e Engenharia de \\ Alimentos \\ E-mail para contato: cinta.soares@ufsc.br
}

\begin{abstract}
RESUMO - A apitoxina, veneno produzido pela abelha Apis mellifera, compõe-se, principalmente, de peptídeos e enzimas, quase todos fisiologicamente ativos, sendo historicamente reconhecida como instrumento valioso para o combate à diversas doenças. Dentre os constituintes da apitoxina, a melitina tem atraído grande atenção ao longo dos anos devido ao seu potencial farmacológico. Porém, visto que os demais constituintes da apitoxina podem apresentar ação deletéria, faz-se necessária a obtenção de melitina com elevado grau de pureza para sua eficiente aplicação na área farmacêutica. Este trabalho tem como objetivo desenvolver uma metodologia de obtenção de melitina a partir do veneno de abelha, de modo a viabilizar a aplicação técnica e econômica desse bioativo. Os componentes alergênicos do veneno foram inicialmente removidos por diferença de peso molecular, através da técnica de GPC e, em seguida, uma purificação mais extensiva da melitina foi realizada utilizando um equipamento de RP-HPLC. Obteve-se um pico referente à melitina em um menor tempo em comparação a outras metodologias da literatura.
\end{abstract}

\section{INTRODUÇÃO}

Diversos organismos produzem "veneno" como instrumento de defesa contra possíveis predadores. As ações fisiológicas são variadas, podendo imobilizar ou até matar a presa. Bem abaixo das doses agressivas, os "venenos" podem ter ações fisiológicas desejáveis e até terapêuticas. Apesar de ser letal para o homem, quando aplicado em grandes proporções, o veneno da abelha (apitoxina) é, paradoxalmente, um consagrado medicamento contra diversos distúrbios e problemas. As propriedades anti-artríticas da apitoxina, por exemplo, são reconhecidas há muitos séculos. Embora a ferroada da abelha induza a dor e o edema local, o veneno da Apis mellifera tradicionalmente tem sido utilizado para tratar doenças inflamatórias e no alívio da dor (Lee et al., 2005).

Dentre os constituintes da apitoxina, a melitina (fração correspondente a, aproximadamente, $50 \%$ em massa do veneno seco) tem atraído grande atenção ao longo dos anos devido ao seu potencial farmacológico (Alves, 2011). Algumas de suas propriedades medicinais relatadas são: 
- estimula a hipófise-adrenal a liberar catecolaminas e corticol, o que lhe confere efeito anti-inflamatório. A ação anti-inflamatória chega a ser mais potente que a cortisona e seus derivados, sobre os quais tem a vantagem adicional de ausência de efeitos colaterais (Lee et al., 2005; Maia, 2002);

- age no sistema cardiovascular, provocando contração dos músculos lisos e do músculo cardíaco. Promove, deste modo, a dilatação dos capilares e diminuição da pressão arterial;

- atua no sistema nervoso central, bloqueando a transmissão de impulsos nervosos, o que provoca um efeito anestésico;

- promove redução dos níveis de colesterol no sangue (Klocek e Seelig, 2008).

Pesquisas recentes têm também demonstrado o potencial da melitina na inibição do crescimento tumoral via estimulação de resposta imunológica (Attia et al., 2008; Liu et al., 2008), bem como na necrose de tecido tumoral (Wang et al., 2009). Além disso, este bioativo tem sido aplicado na elaboração de formulações cosméticas destinadas à recuperação do tecido epidérmico, porém sem comprovação de seu eficácia. Suspeita-se que ela interaja sinergicamente com as fibras do colágeno. Desta forma, a melitina tem sido apontada como um potencial substituto da toxina botulínica no tratamento cosmético facial.

A apitoxina é sintetizada na glândula de veneno das abelhas-operárias e de abelhas-rainhas a partir de uma mistura de secreções ácidas e básicas de modo a formar uma secreção ácida com pH entre 4,5 e 5,5, a qual é armazenada em suas bolsas de veneno. Esse veneno é uma mistura complexa que contém moléculas orgânicas simples, proteínas, peptídeos e outros elementos bioativos. Diversos destes componentes foram isolados e caracterizados e as suas estruturas primárias foram determinadas por técnicas bioquímicas (Lima e Brochetto-Braga, 2003). Son e colaboradores (2007) relataram que o veneno de abelha contém uma variedade de peptídeos, incluindo a melitina, apamina, adolapina e o peptídeo MCD, enzimas (fosfolipase A2), aminas biologicamente ativas (histamina e epinefrina) e componentes não peptídicos, os quais têm uma variedade de propriedades farmacêuticas (Son et al., 2007).

A apitoxina é basicamente uma mistura complexa de compostos nitrogenados que correspondem a mais de $90 \%$ do seu peso seco. Na Tabela 1 encontram-se relacionados seus principais componentes, agrupados por faixas de peso molecular.

Observa-se que os componentes nitrogenados com peso molecular abaixo de $1.000 \mathrm{Da}$ consistem, principalmente, de pequenos peptídeos e monoaminas. Na faixa entre $1.000 \mathrm{e}$ 10.000 Da encontram-se numerosos polipeptídeos, com amplo predomínio da melitina. Acima de 10.000 Da ocorrem diversas enzimas, com amplo predomínio da fosfolipase A2. No total, a apitoxina contém cerca de 20 substâncias ativas.

Os componentes mais alergênicos da apitoxina são as enzimas com peso molecular acima de $10.000 \mathrm{Da}$ e os de interesse terapêutico são cadeias com peso molecular entre $2.000 \mathrm{e}$ 3.000 Da, além de outros ainda menores. Partindo desta premissa, faz-se necessária a obtenção de melitina com elevado grau de pureza para sua eficiente aplicação na área farmacêutica. Além 
disso, de modo a viabilizar a aplicação técnica e econômica desse bioativo, é crucial o desenvolvimento de estratégias eficientes de escalonamento do processo de separação e purificação para produção comercial. Diversas metodologias para a separação e purificação são encontradas na literatura (Chen et al., 2006). Todavia, elas não descrevem precisamente os parâmetros necessários para a reprodutibilidade dos experimentos. A abrangência de diferentes equipamentos utilizados em cada uma das metodologias também dificulta a reprodução desses experimentos. Com base no exposto, a elaboração de um procedimento com equipamentos mais comuns e um estudo aprofundado das operações de separação e purificação faz-se necessário. Desta forma, este trabalho tem por objetivo o desenvolvimento de uma metodologia para a obtenção de melitina com elevado grau de pureza a partir do veneno bruto de abelha.

Tabela 1- Principais componentes da apitoxina

\begin{tabular}{cccc}
\hline $\begin{array}{c}\text { Peso molecular } \\
(\text { Da) }\end{array}$ & Componente & $\begin{array}{c}\text { \% (base } \\
\text { seca) }\end{array}$ & Observações \\
\hline \multirow{2}{*}{$<1000$} & Peptídeos & 15 & Cadeias de até 9 aminoácidos \\
& Monoaminas & 3 & $\begin{array}{c}\text { Histamina, dopamina, noradrenalina } \\
\text { Aminoácidos isolados, carboidratos, } \\
\text { fosfolípides. }\end{array}$ \\
& Outros & 6 & Anti-inflamatório \\
Polipeptídeos & Melitina & 50 & Anti-inflamatório \\
1000 a 10.000 & Apamina & 2 & Anti-inflamatório \\
& Peptídeo & 2 & Tertiapina, secapina, cardiopep. \\
\hline \multirow{2}{*}{ Enzimas } & Outros & 3 & Principal alergênico \\
$>10.000$ & Fosfolipase & 12 & Alergênico secundário \\
& Hiauronidase & 2 & Fosfatase ácida, a-glucosidase, \\
& Outras & 3 & esterases \\
\hline Outras substâncias & 2 & Adolapina, inibidor de protease \\
\hline
\end{tabular}

Fonte: Maia, 2002; Müller et al., 1997.

\section{METODOLOGIA}

O veneno de abelha foi coletado utilizando-se um equipamento apropriado (Figura 1) disponível comercialmente e adquirido junto a empresa Apiários Montanha (Torrecilha). Durante a extração do veneno, a abelha é induzida a ferroar a placa coletora através de choques elétricos, sem levá-la ao óbito, uma vez que a mesma não perde seu "ferrão". Em particular, o aparelho utilizado neste estudo tem capacidade para atender dez colmeias simultaneamente. 


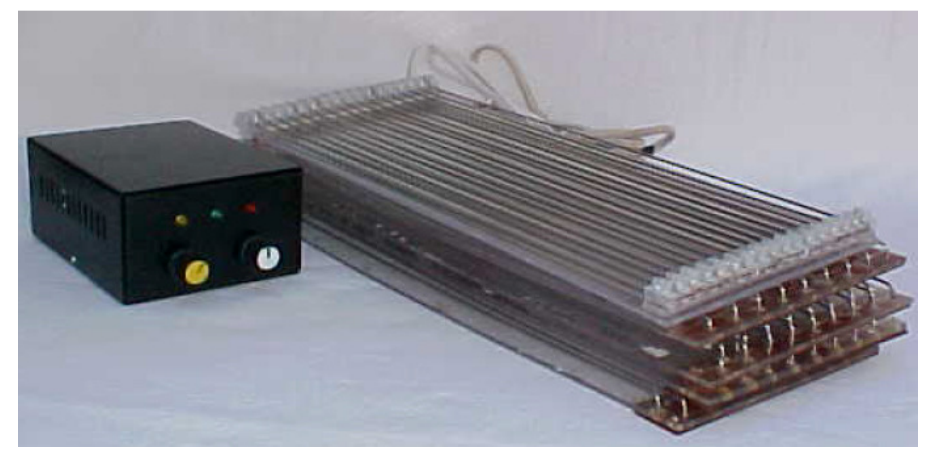

Figura 1 - Equipamento coletor de apitoxina composto de placas coletoras e gerador de pulsos.

O gerador de pulsos do equipamento é alimentado por uma bateria de pequeno porte, capaz de gerar um potencial de $12 \mathrm{~V}$ e corrente de $2 \mathrm{~A}$. A placa coletora, alimentada pelo gerador de pulsos, possui estrutura de acrílico com varetas para condução de corrente elétrica construídas em aço inox (para que não haja contaminação do produto). Cada colmeia recebe uma placa coletora que é capaz de extrair, aproximadamente, $100 \mathrm{mg}$ de veneno por colmeia. O tempo de coleta foi de 20 min e, após coletado, o veneno de abelha foi raspado das placas e acondicionado em frasco âmbar a uma temperatura de $-10^{\circ} \mathrm{C}$.

Aproximadamente $200 \mathrm{mg}$ de veneno de abelha bruto foram dissolvidos em $4 \mathrm{~mL}$ de uma solução de $0,01 \mathrm{~mol} / \mathrm{L}$ de ácido acético (Reagen) e, então, centrifugados a $3.500 \mathrm{rpm}$ por $10 \mathrm{~min}$ (CentriBio 80-2B). O precipitado foi removido e o sobrenadante alimentado em uma coluna de cromatografia de permeação em gel, a qual é composta de uma coluna de vidro C 16/70 (GE Healthcare) contendo gel cromatográfico Sephadex ${ }^{\circledR}$ G-10 (GE Healthcare). O gel foi préequilibrado com solução tampão de acetato de amônio com concentração de $0,05 \mathrm{~mol} / \mathrm{L}$ (Reagen). Essa mesma solução foi utilizada como fase móvel.

Uma taxa de eluição de $1 \mathrm{~mL} / \mathrm{min}$ foi aplicada à coluna e a fase móvel foi coletada em tubos de ensaio ( $5 \mathrm{~mL} /$ tubo) na saída do equipamento. Foi realizado, então, o monitoramento das amostras coletadas através de equipamento de espectrofotometria UV (Hach) em $280 \mathrm{~nm}$. Esta etapa tem o intuito de separar os componentes por diferença de massa molecular, uma vez que a melitina (composto de interesse) possui massa molecular de $2.847 \mathrm{Da}$ e os componentes alergênicos, como a fosfolipase A2 e a hiarulonidase, possuem massa molecular entre $15.000 \mathrm{e}$ $40.000 \mathrm{Da}$.

A purificação das frações obtidas na coluna de permeação em gel foi realizada num equipamento de cromatografia líquida de alto desempenho com fase reversa, RP-HPLC, utilizando uma coluna C-18 (Phenomenex ODS-UG-5, 25×0.5 cm) instalado em um HPLC padrão (Shimadzu LC-20A Prominence). As fases móveis empregadas foram uma solução aquosa A de ácido trifluoracético (Reagen) 0,01 \% e uma solução B de acetonitrila (Reagen). Para a eluição, inicialmente utilizou-se um gradiente linear de $85 \%$ do solvente A e $15 \%$ do solvente B para $70 \%$ solvente A e $30 \%$ solvente B em 30 min. Em seguida foi aplicada uma rampa para $85 \%$ solvente A e $15 \%$ solvente B até 35 min. Por fim, uma eluição isocrática nessas 
condições até $37 \mathrm{~min}$. A análise foi monitorada em $215 \mathrm{~nm}$ com uma com taxa de eluição de 1,0 $\mathrm{mL} / \mathrm{min}$.

\section{RESULTADOS E DISCUSSÃO}

\subsection{Separação dos componentes alergênicos}

O cromatograma obtido na Figura 2 demonstra a obtenção de três frações. Uma fração majoritária $\mathrm{F} 1$, a qual acredita-se ser a fração que contém a melitina (de acordo com experimentos similares da literatura (Chen et al., 2006)), e outras duas frações, F2 e F3, de menor massa molecular. A varredura de seus respectivos espectros na Figura 3 demonstrou que se trata de três componentes distintos, com o adendo de que a fração F3 pode conter também o mesmo componente da fração F1, porém em concentração muita mais baixa, tendo em vista o espectro similar na faixa de 230 a $300 \mathrm{~nm}$. Esse experimento também ressaltou que a leitura mais adequada para o monitoramento no equipamento de RP-HPLC deveria ser de $215 \mathrm{~nm}$ para estas frações.

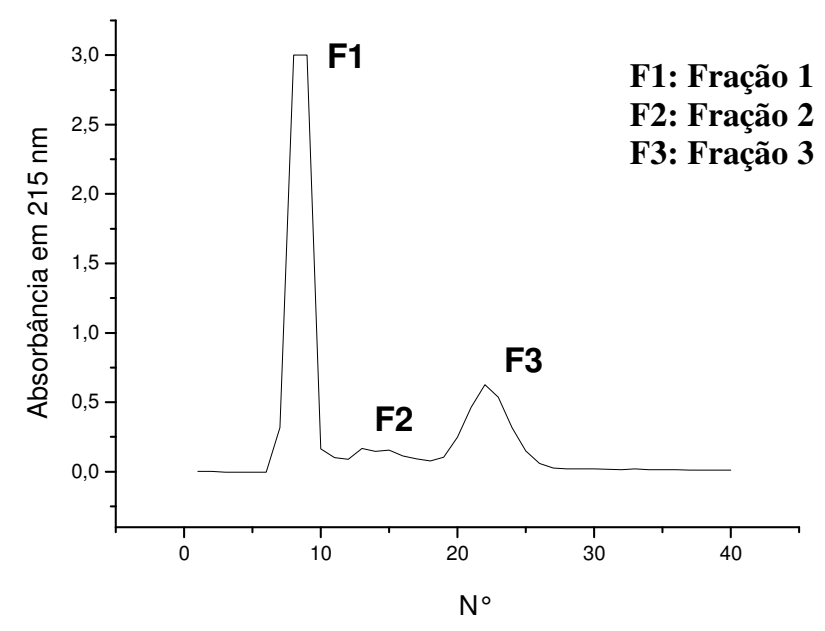

Figura 2 - Cromatograma das frações obtidas do veneno de abelha bruto por meio de GPC.

A fim de verificar as diferenças de componentes entre as frações F1, F2 e F3 obtidas na coluna de GPC, foram realizadas varreduras espectrofotométricas entre 190 a $500 \mathrm{~nm}$. A fração F1 foi diluída numa proporção de 1:3. As frações F2 e F3 não foram diluídas. Os resultados estão ilustrados na Figura 3. 

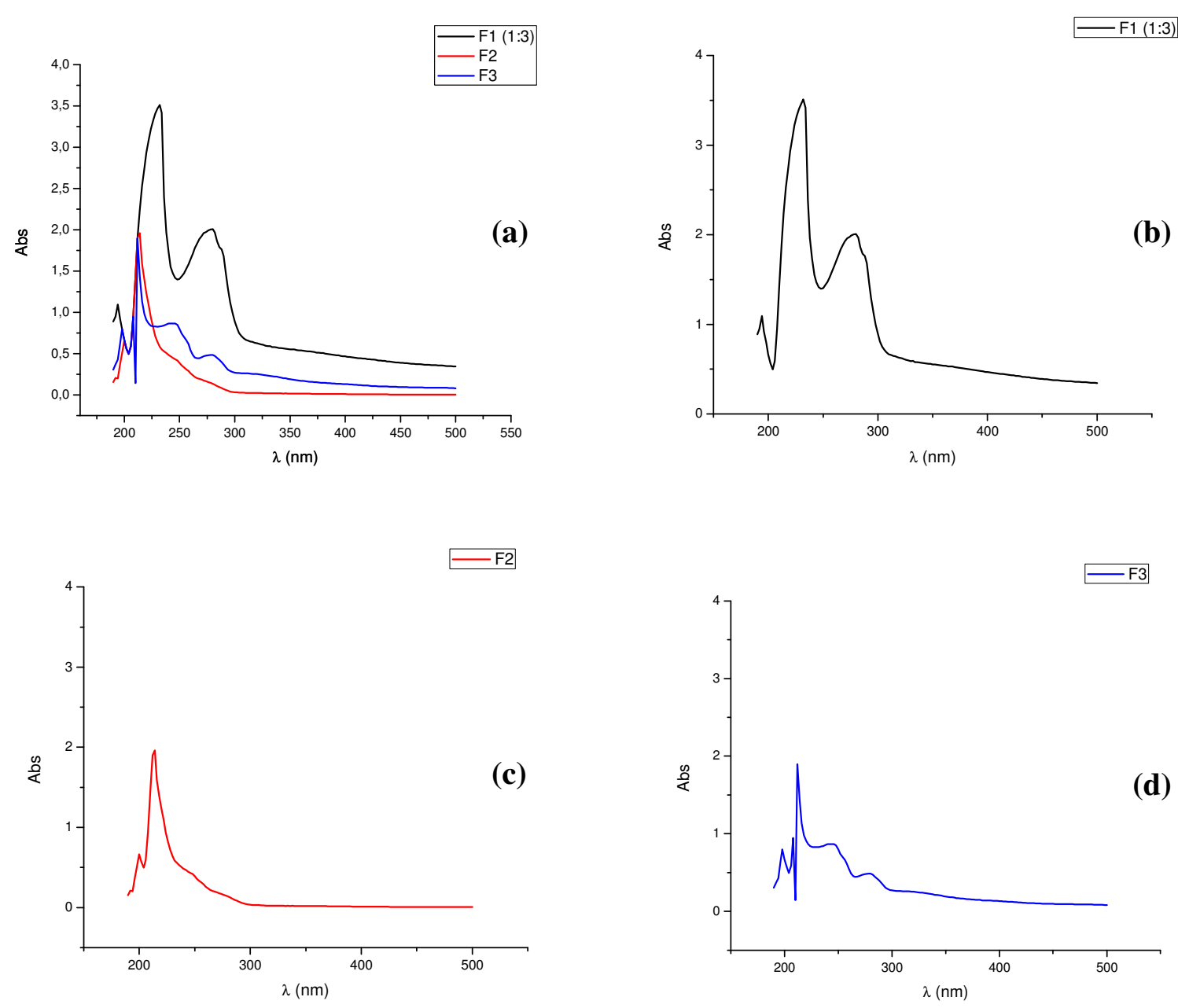

Figura 3 - Espectros comparativos das frações F1, F2 e F3 (a); espectro da fração F1 (b); espectro da fração F2 (c); espectro da fração F3 (d).

\subsection{Purificação da melitina}

A fração F1 obtida por GPC foi injetada num sistema de RP-HPLC com o intuito de apurar a obtenção da melitina através da comparação com uma amostra padrão. O objetivo também foi verificar a existência de impurezas presentes nesta fração para um posterior estudo de purificação. $O$ cromatograma obtido está ilustrado na Figura 4. 


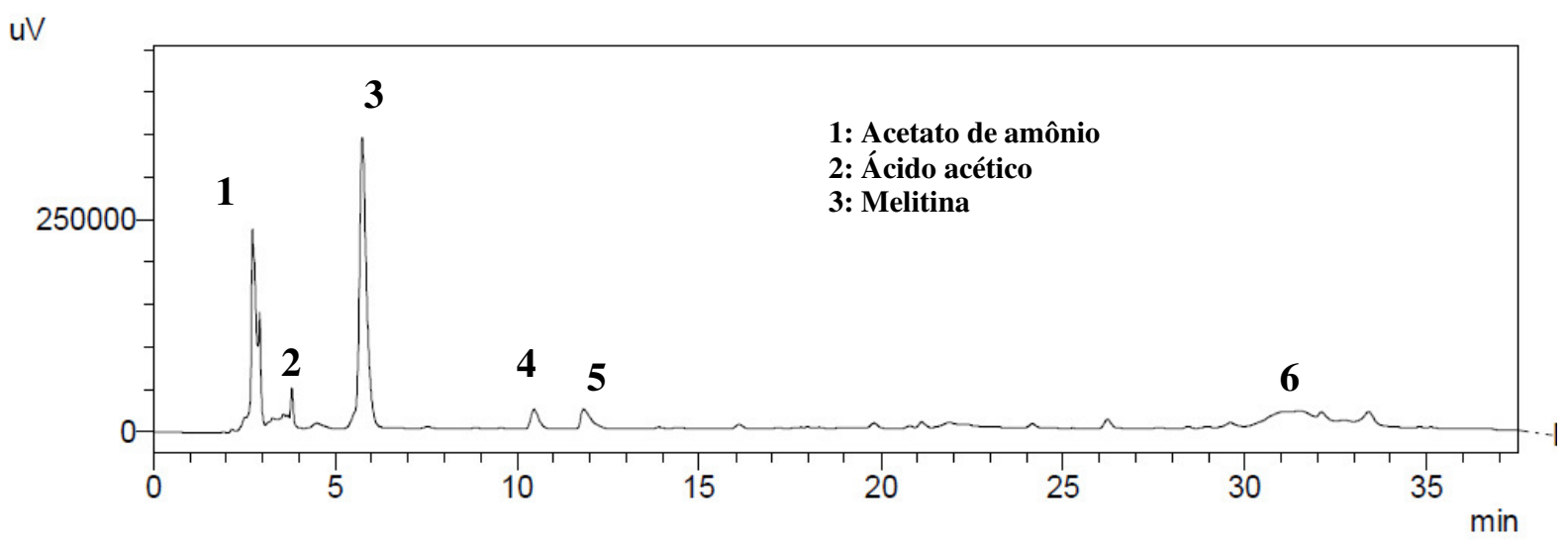

Figura 4 - Cromatograma da fração F1 obtido por RP-HPLC.

Os picos 1 e 2 foram identificados como sendo acetato de amônio e ácido acético, eluentes utilizados na etapa de GPC. O pico 3 acredita-se ser a melitina, componente majoritário do veneno e o componente de interesse, de acordo com resultados semelhantes encontrados na literatura (Chen et $a l ., 2006)$. Ressalta-se a grande diminuição do tempo de retenção (em aproximadamente 10 min) para o pico correspondente a melitina em relação à metodologia utilizada por Chen e colaboradores (2006).

\section{CONCLUSÃO}

O cromatograma obtido por RP-HPLC apresenta picos que correspondem a compostos que ainda precisam ser identificados. A fração 3, que representa o pico mais intenso do cromatograma, possui grande possibilidade de corresponder à melitina, uma vez que esse peptídio é o composto mais abundante no veneno da Apis melifera. Ainda assim, são necessários estudos mais aprofundados a respeito desta fração para uma identificação da sequência completa destes peptídeos. Pretende-se caracterizar esses peptídeos através de padrões e por espectrometria de massa MALDI-TOF. Além disso, uma comparação entre a fração F1 obtida por GPC e o veneno bruto se faz necessária para se comprovar a exclusão dos componentes alergênicos.

Diferentes ensaios, com base em um comparativo entre eluição isocrática e diferentes gradientes de eluição na etapa de purificação estão sendo realizados a fim de se obter picos mais espaçados e com maior resolução, para a partir daí, trabalhar em cima de uma purificação no menor tempo possível. Estuda-se também a possibilidade da utilização de solventes alternativos, como o etanol, para a ampliação de escala.

\section{AGRADECIMENTO}

Os autores agradecem à CAPES pela bolsa de estudos.

\section{REFERÊNCIAS}

ALVES, E. M. Processo de produção de bioprodutos elaborados com componentes isolados de 
apitoxinas de abelhas Apis mellifera, composição e uso. INPI. RPI 21102011.

ATTIA, W. Y.; GABRY, M. S.; EL-SHAIKH, K. A.; OTHMAN, G. A. The anti-tumor effect of bee honey in Ehrlich ascite tumor model of mice is coincided with stimulation of the immune cells. Egypt. J. Immunol., v. 15, p. 169-183, 2008.

CHEN, Y. N.; LI, K.-C.; LI, Z.; SHANG, G.-W.; LIU, D. N.; LU, Z. M.; ZHANG, J.-W.; JI, Y.-H. GAO, G.-D.; CHEN, J. Effects of bee venom peptidergic components on rat pain-related behaviors and inflammation. Neuroscience, v. 138, p. 631-640, 2006.

KLOCEK, G.; SEELIG, J. Melittin interaction with sulfated cell surface sugars. Biochemistry, v. 47, p. 2841-2849, 2008.

LEE, J. D.; PARK, H.-J.; CHAE, Y.; LIM, S. An overview of bee venom acupuncture in the treatment of arthritis. Evid.-Based Compl. Alt., v. 2, p. 79-84, 2005.

LIMA, P. R. D.; BROCHETTO-BRAGA, M. R. Hymenoptera venom review focusing on Apis mellifera. J. Venom. Anim. Toxins, v. 9, p. 149-162, 2003.

LIU, S.; YU, M.; HE, Y.; XIAO, L.; WANG, F.; SONG, C.; SUN, S.; LING, C.; XU, Z. Melittin prevents liver cancer cell metastasis through inhibition of the Rac1-dependent pathway. Hepatology, v. 47, p. 1964-1973, 2008.

MAIA, A. B. O potencial terapêutico da apitoxina. Mensagem Doce: Apacame, 2002.

MÜLLER, U.; FRICKER, M.; WYMANN, D.; BLASER, K.; CRAMERI, R. Increased specificity of diagnostic tests with recombinant major bee venom allergen phospholipase A2. Clin. Exp. Allergy, v. 27, p. 915-920, 1997.

SON, D. J.; LEE, J. W.; LEE, Y. H.; SONG, H. S.; LEE, C. K.; HONG, J. T. Therapeutic application of anti-arthritis, pain-releasing and anti-cancer effects of bee venom and its constituent compounds. Pharmacol. Therapeut., v. 115, p. 246-270, 2007.

TORRECILHA, M. Apiários Montanha. Disponível em: <http://www.apiariosmontanhas.com/>.

WANG, C.; CHEN, T.; ZHANG, N.; YANG, M.; LI, B.; LÜ, X.; CAO, X.; LING, C. Melittin, a major component of bee venom, sensitizes human hepatocellular carcinoma cells to tumor necrosis factor-related apoptosis-inducing ligand (TRAIL)-induced apoptosis by activating CaMKII-TAK1-JNK/p38 and inhibiting I kappa B alpha kinase-NF kappa B. J. Biol. Chem., v. 284, p. 3804-3813, 2009. 